\title{
PENGENDALIAN MODUL OVERHEAD HANDLING STATION BERBASIS SEQUENTIAL FUNCTION CHART
}

\author{
Winwin $^{1)}$, Soeharsono ${ }^{1)}$ dan Agus Halim ${ }^{2)}$ \\ Program Studi Teknik Mesin Universitas Tarumanagara, Jakarta \\ e-mail: winmylive8@gmail.com
}

\begin{abstract}
Abstrak: Penelitian ini berisi hasil pengujian dan simulasi pada stasiun penanganan overhead dimana stasiun berada dalam otomasi sistem distribusi. Tujuan dari penelitian ini adalah untuk membuat suatu program di bidang komputasi dan overhead handling station agar berjalan bila dikombinasikan dengan program yang sesuai yang telah dibuat. Modul stasiun penanganan overhead ini adalah bagian dari mesin otomasi yang mendistribusikan simulasi proses objek berongga dan tidak berongga, maka PLC harus mengendalikan semua sistem modul stasiun penanganan overhead yang sesuai dengan sistem yang Anda inginkan. Untuk mengendalikan sistem kerja, bahasa pemrograman yang mudah dipahami sangat dibutuhkan seperti functional block diagram (FBD) dimana diagram blok fungsional adalah metode yang dapat menggambarkan fungsi antara variabel input dan output. Dalam FBD ada metode bagan fungsi sekuensial (SFC) yang mengendalikan aktivitas sekuensial program. Jadi penelitian ini membahas tentang pengendalian modul pengolahan yang menggunakan bahasa pemrograman FBD dengan menggunakan metode SFC.
\end{abstract}

Kata Kunci: Otomasi, Distribusi, Modul Stasiun Penanganan Overhead, Programmable Logic Controller, Fungsional Block Diagram, Sequential Function Chart.

\begin{abstract}
This study contains the results of the testing and simulation research on overhead handling station where the station is in the distribution system automation. The purpose of this study to create a program in computing and overhead handling station to run when combined with appropriate program that have been created. This overhead handling station module is a part of the automation engine which distribution a process simulation of hollow and not hollow objects, then a PLC is to be need to control all of the working overhead handling station modules systems which system works as you want. To control a working system, a programming language that easily to be understood is needed such as functional block diagram (FBD) which the functional block diagram is a method that can describe a function between input and output variable. In FBD there is a sequential function chart method (SFC) which control the program sequential activity. So this research discusses the control of processing module which using FBD programing language by using the SFC method.
\end{abstract}

Keywords: Automation, Distribution, Overhead Handling Station Module, Programmable Logic Controller, Functional Block Diagram, Sequential Function Chart.

\section{PENDAHULUAN}

Dasar pembuatan program kendali pada PLC diadopsi dari sistem kendali konvensional yang menggunakan berbagai peralatan kendali, seperti: relay, timer, counter, dsb. Dengan kata lain, PLC dapat menggantikan peralatan kendali pada sistem kendali konvensional, Dan kenyataannya peran PLC telah menggantikan fungsi dari relay. Untuk itu, PLC membutuhkan support software seperti Zelio Soft 2 untuk menuliskan program yang dibutuhkan untuk suatu jenis aplikasi tertentu.[3]

Salah satu sistem otomasi yang sering dipakai dalam dunia industri adalah sistem distribusi. Contoh sistem distribusi dapat diuraikan dalam berbagai macam aplikasi yaitu:

1. Sistem Overhead Handling Station/ Distrtibuting.

2. Sistem Lifting.

3. Sistem Gripping.

Sistem overhead handling station adalah station dimana lengan dapat bergerak secara vertikal untuk mendistribusikan benda kerja kepada sistem storage station. Sistem lifting adalah sistem dimana lengan yang mendistribusikan benda kerja dapat bergerak secara horizontal. Dan terakhir adalah sistem gripping. Sistem gripping adalah sistem penggenggam benda kerja. 


\section{Perumusan Masalah}

Mensimulasikan sistem pada modul overhead handling station skala labolatorium, menggunakan program Sequential Function chart (SFC).

\section{Kajian Pustaka}

Sequential Function Chart (SFC) adalah bahasa pemrograman grafis yang digunakan untuk Programmable Logic Controller (PLC). SFC berguna sebagai alat pemodelan dan analisis suatu sistem otomasi yang berurutan karena untuk menguraikan siklus mesin dalam rangkaian Sequential Function Chart (SFC).

Fungsi-fungsi dari simbol Sequential Function Chart (SFC) antara lain:

1. Reset initial:

Berfungsi sebagai step awal yang memiliki fungsi reset. Fungsi reset tersebut berguna untuk memutuskan step transisi.

2. Initial Step:

Berfungsi sebagai step awal untuk menerima input dan menyalakan output. Namun berbeda dengan reset initial karena initial step tidak memiliki fungsi reset.

3. Divergen or:

Berfungsi mencabangkan step transisi untuk membuat dua buah jalur proses step.

4. Convergen or:

Berfungsi menggabungkan lebih dari satu jalur proses step.

5. Divergen end:

Berfungsi mengaktifkan dua buah step sekaligus hanya dengan satu input step.

6. Convergen and:

Berfungsi mengaktifkan proses step jika terdapat dua buah input step yang aktif.

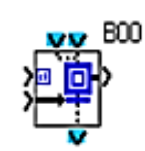

Reset init

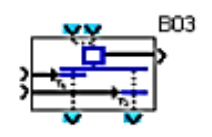

div. or

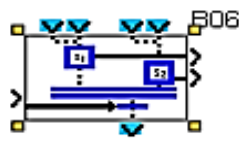

Conv. and

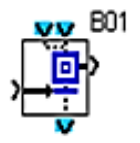

Init step

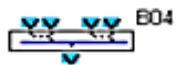

Conv. or

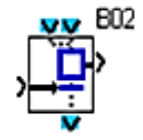

step

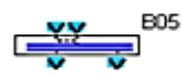

div. end

Gambar 1. Simbol-Simbol Pada Sequential Function Chart (SFC) 


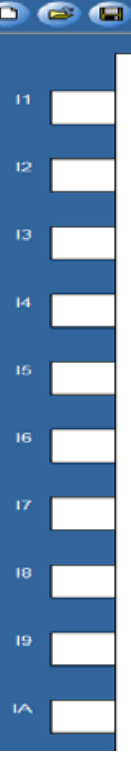

Keterangan Gambar:

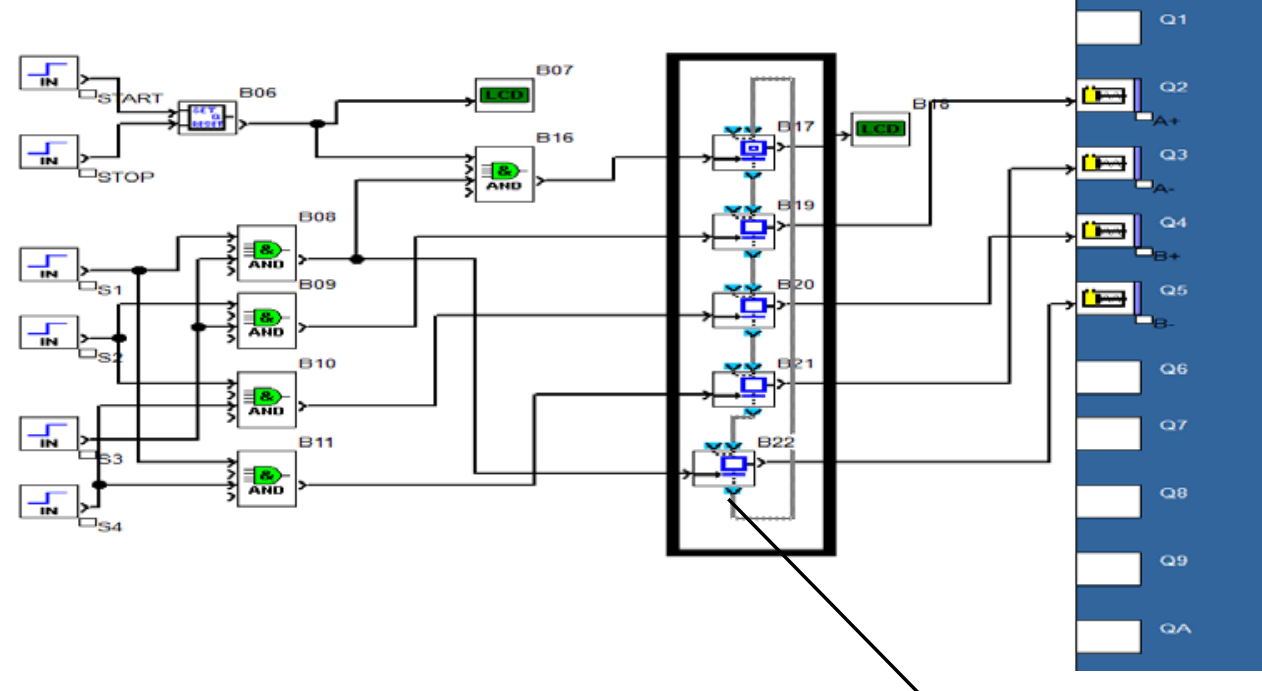

Gambar 2. Program Sequential Function Chart (SFQ)

1. Sequential Function Chart (SFC).

\section{METODE PENELITIAN}

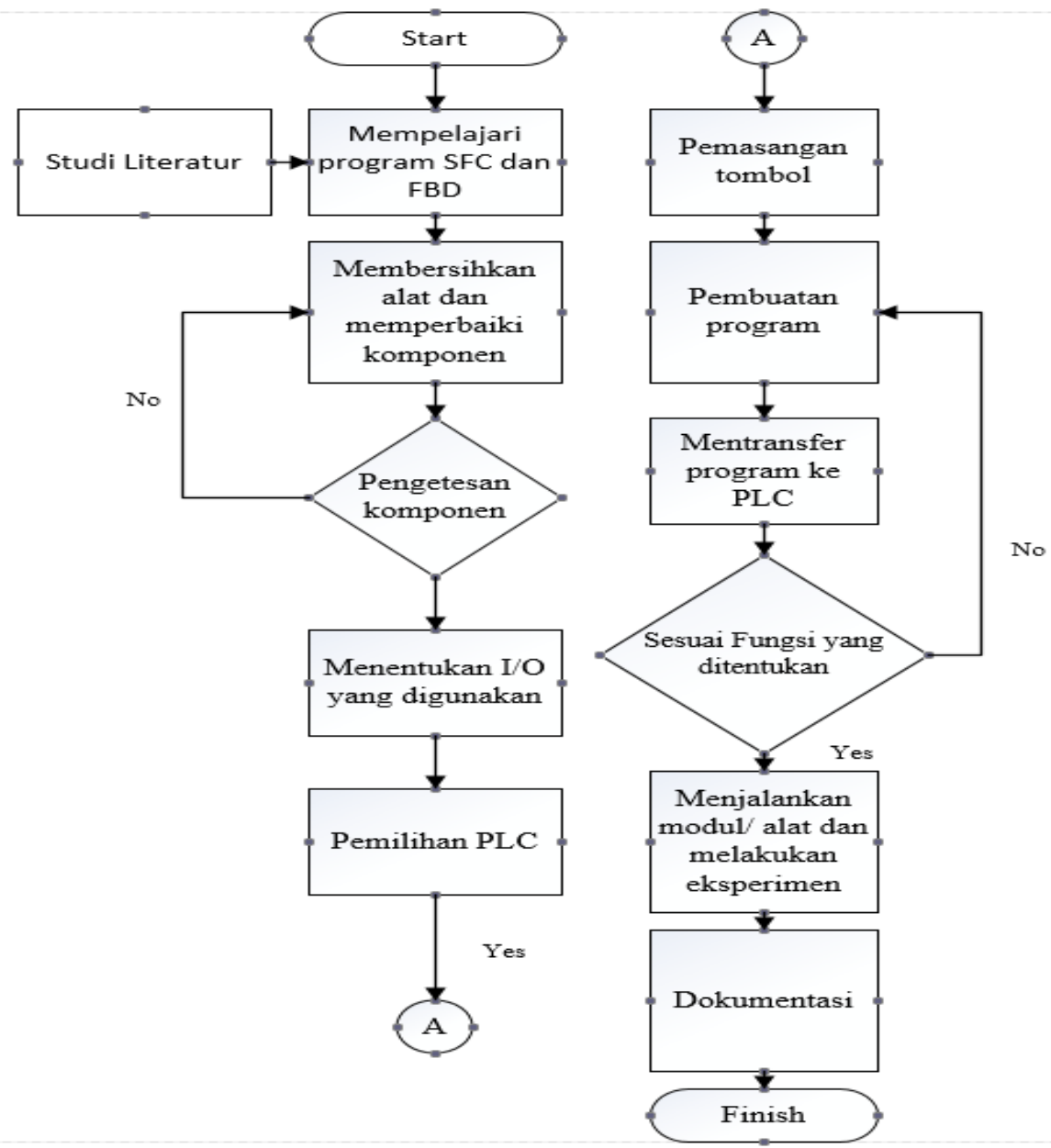

Gambar 3. Diagram Alir Perancangan 
- Bahan dan Alat Yang Digunakan

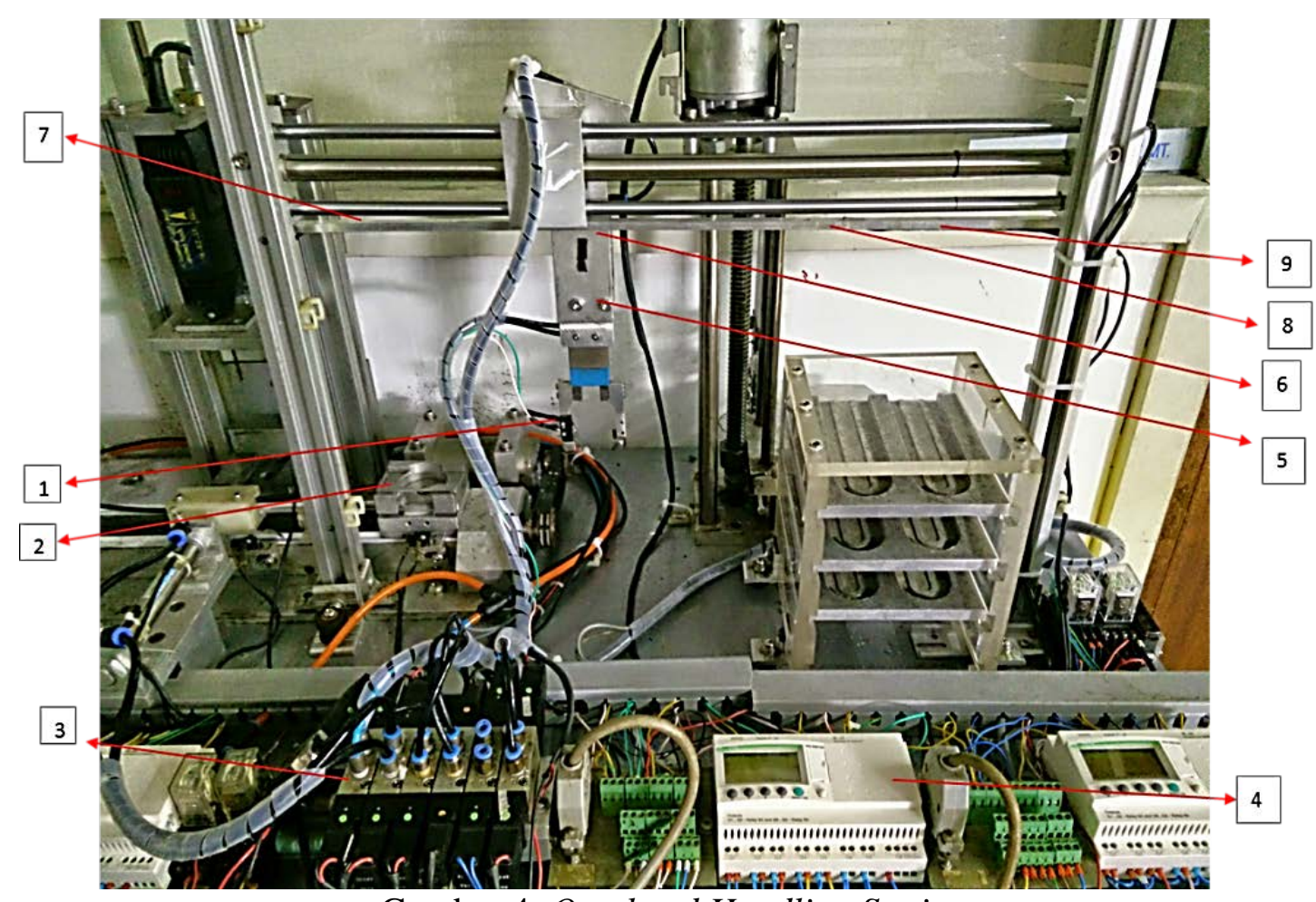

Gambar 4. Overhead Handling Station

Keterangan gambar:

1. Limit Switch (G)

2. Sensor Photoelectric (BD)

3. Direct Control Valve

4. PLC

5. Sensor Proximity (L1)
6. Sensor Proximity (L2)

7. Sensor Proximity (H1)

8. Sensor Proximity (H2)

9. Sensor Proximity (H3)

\section{HASIL DAN PEMBAHASAN}

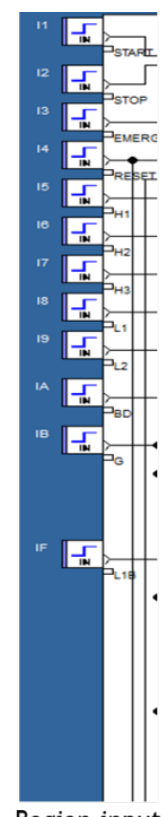

Bagian input

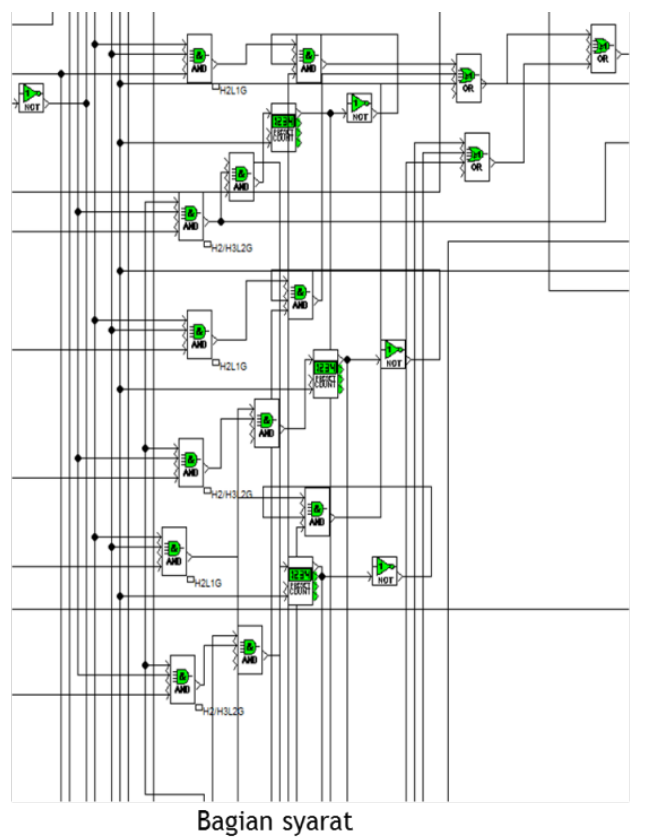

Bagian syarat

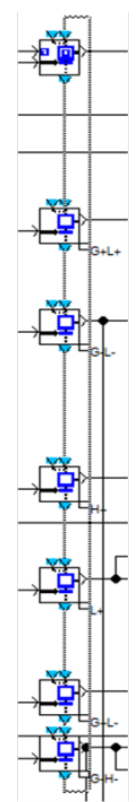

Bagian SFC

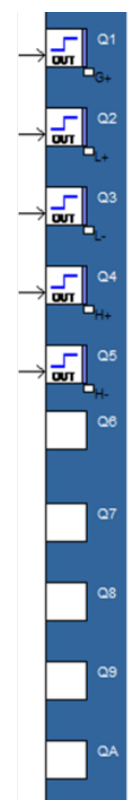

Bagian output

Gambar 5. Program Sequential Function Chart Modul Overhead Handling Station 

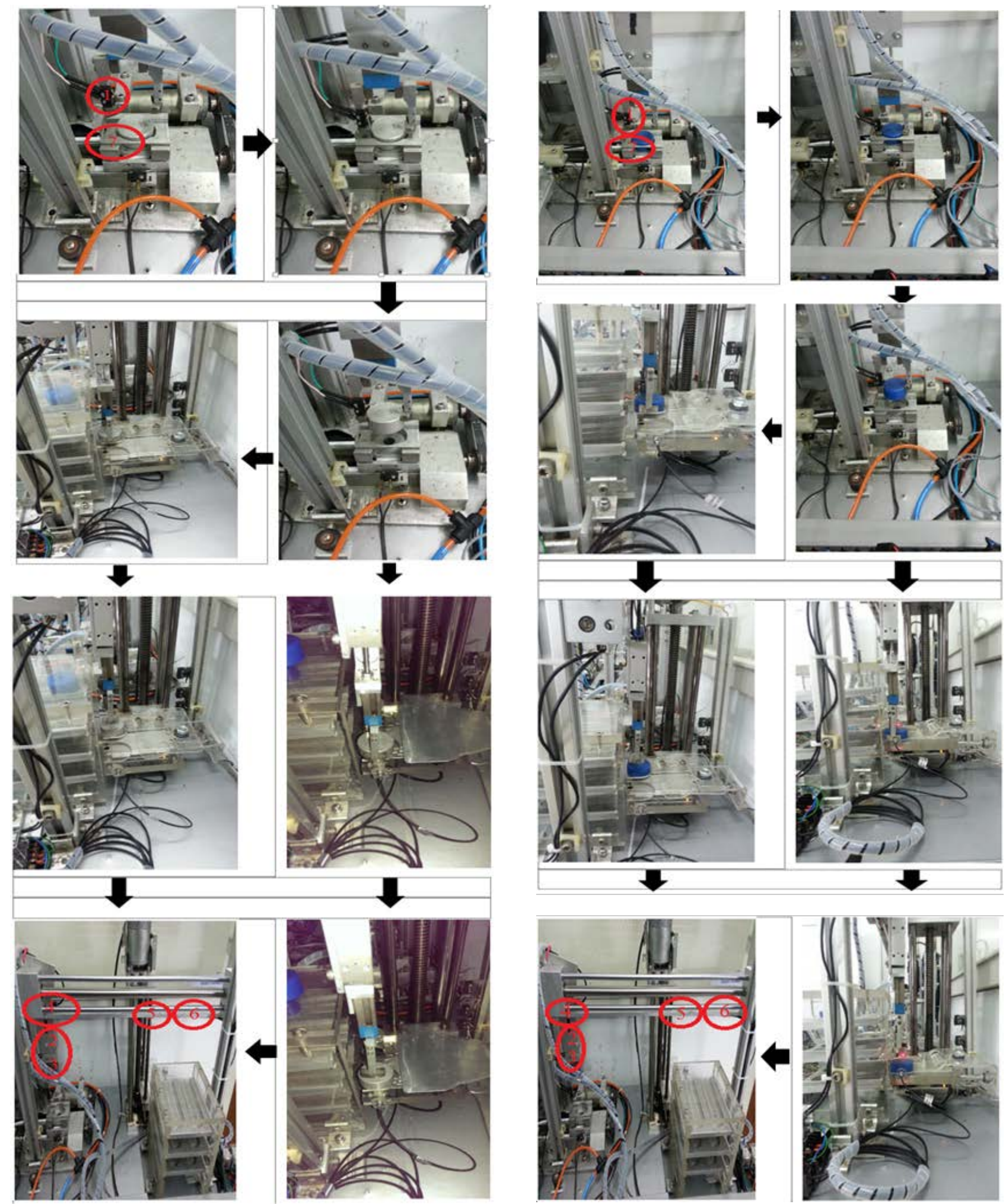

Gambar 6. Pengujian Benda Logam Tidak Berlubang

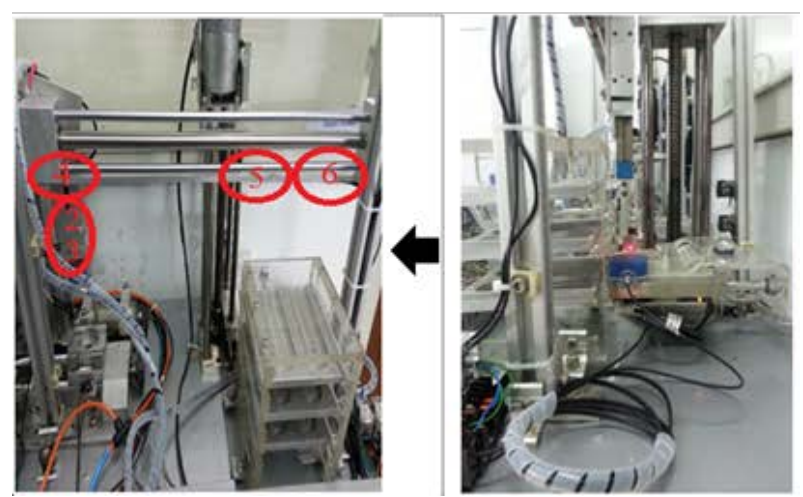

Gambar 7. Pengujian Benda Nonlogam Tidak Berlubang 

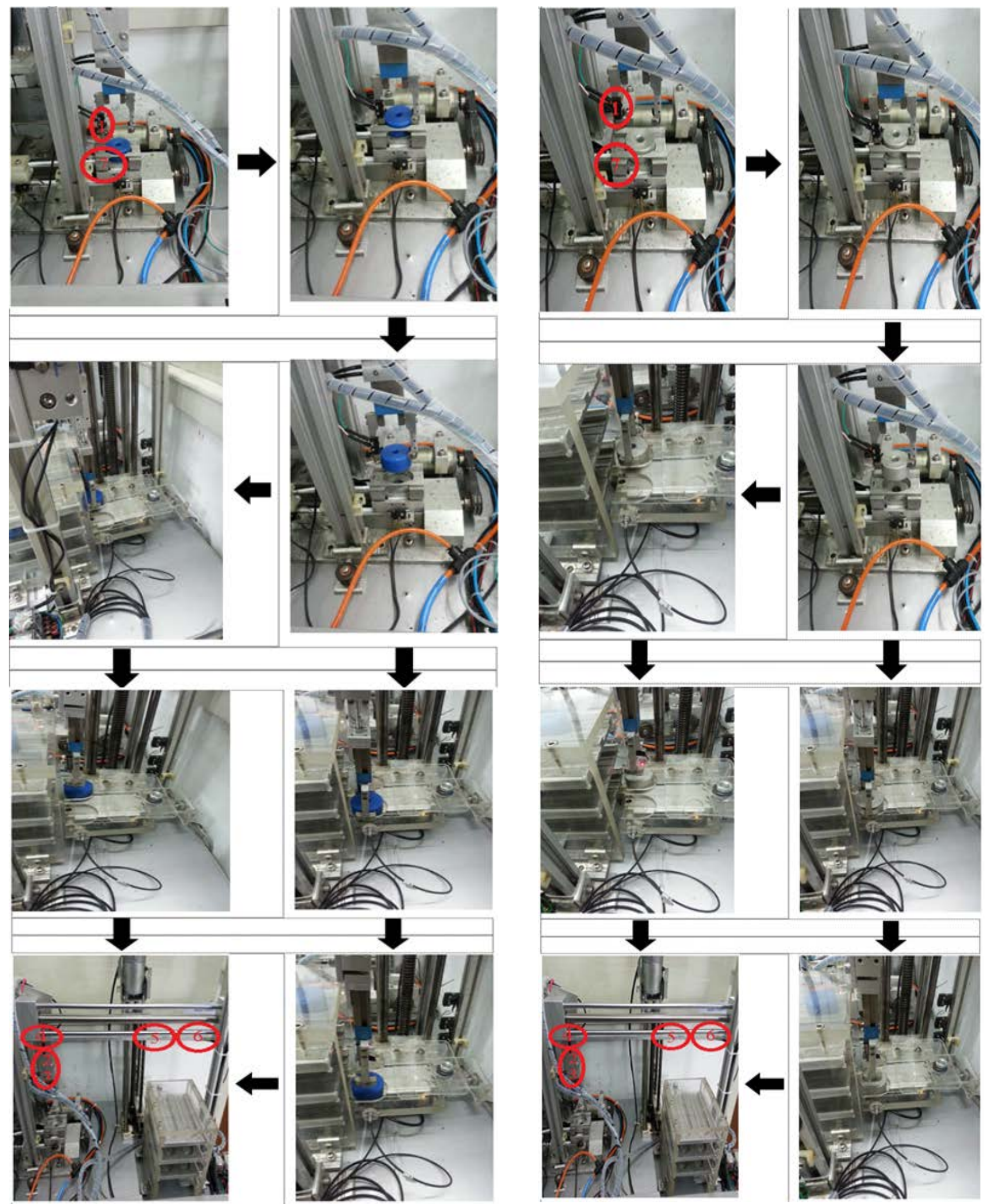

Gambar 8. Pengujian Benda Nonlogam Berlubang
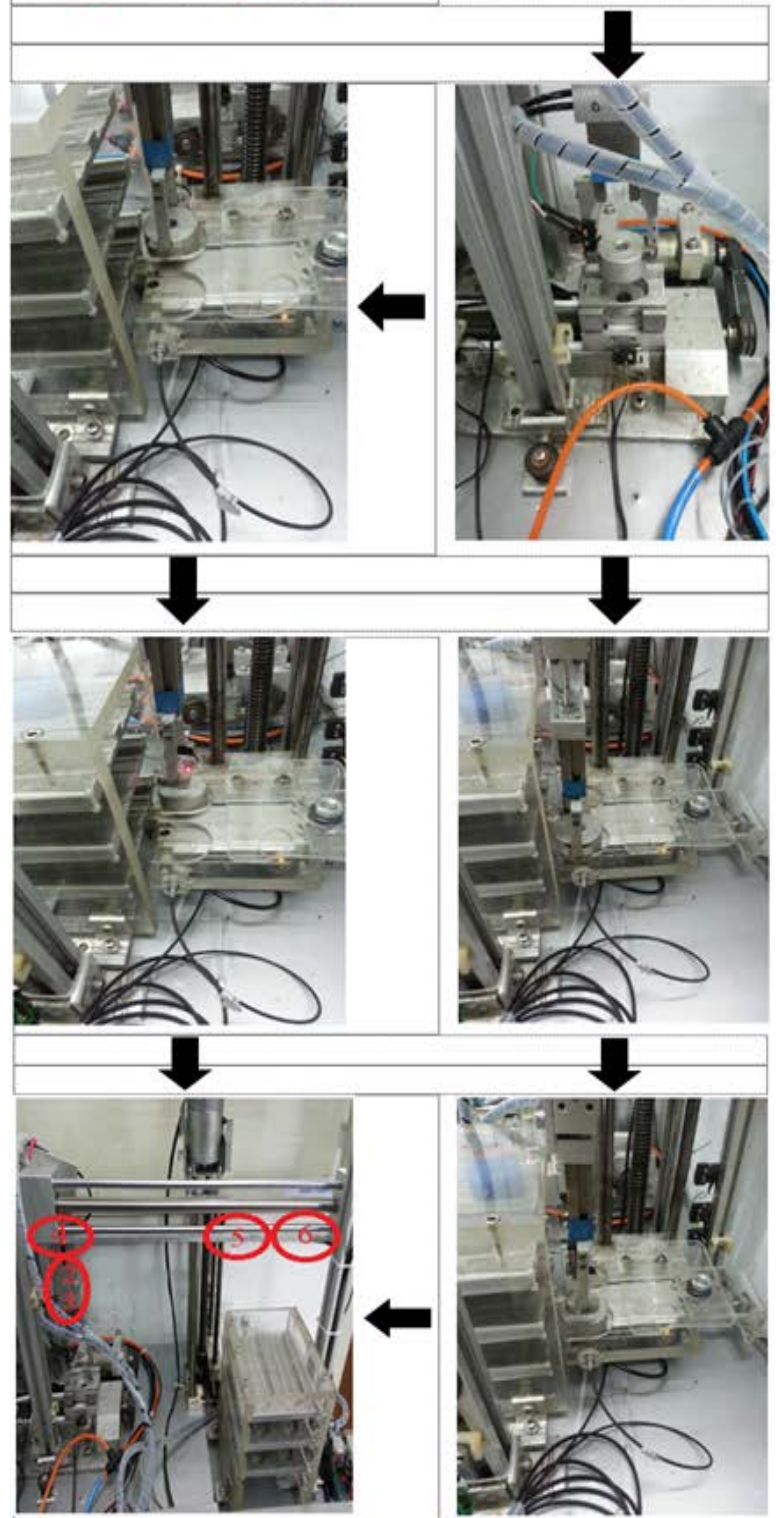

Gambar 9. Pengujian Benda berlubang 


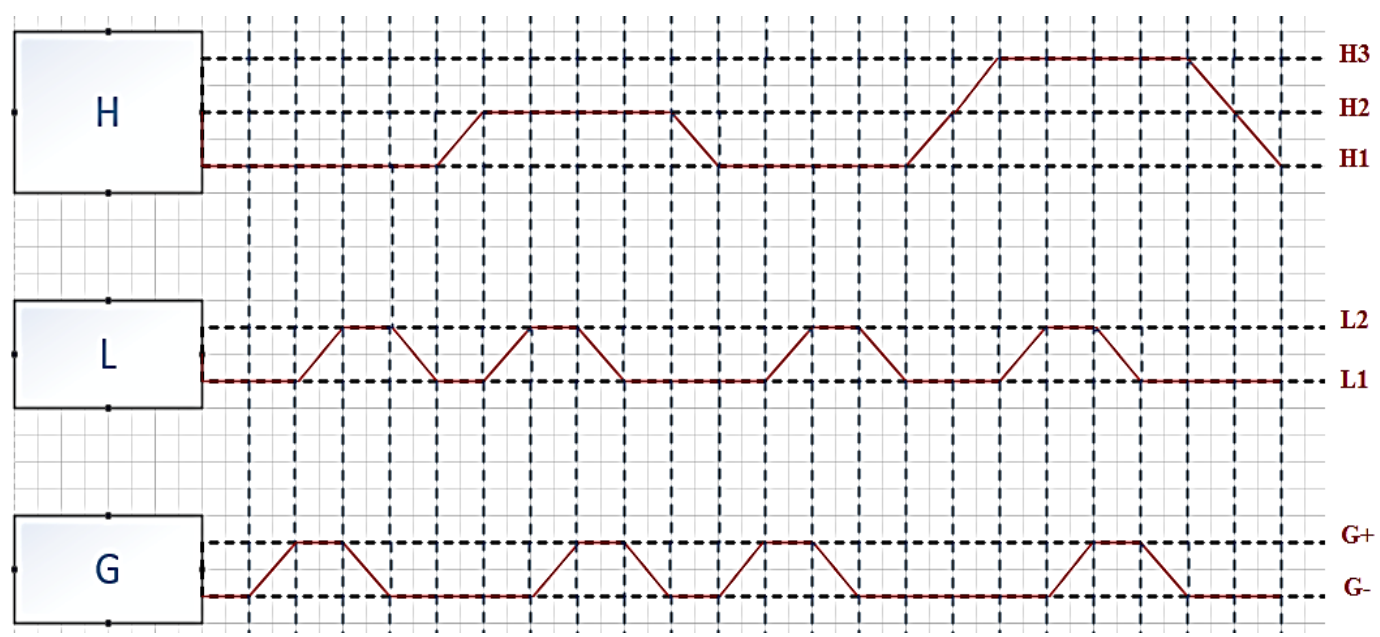

Gambar 10. Diagram step proses pengujian benda berlubang/tidak berlubang

\section{KESIMPULAN}

1. Semua peralatan dan program sequential function chart dinyatakan berhasil karena sistem berjalan sesuai rencana dalam skala laboratorium.

2. Proses pada benda logam tidak berlubang, benda non-logam tidak berlubang dan benda logam/non-logam berlubang berhasil dan tidak terjadi kesalahan dalam proses modul overhead handling station.

3. Kinerja modul overhead handling station sudah mencapai kinerja yang baik dengan repeat ability distribusi sebesar $100 \%$ pada 8 kali pengujian.

4. Dari Jumlah $I / O$ PLC disediakan input berjumlah 16 buah dan output berjumlah 10 buah. Dan I/O PLC yang digunakan dalam modul overhead handling station ini adalah input yang berjumlah 15 buah dan output berjumlah 5 buah serta jumlah program yang digunakan berjumlah 1 buah.

\section{DAFTAR PUSTAKA}

[1]. Elsevier. Introduction to PLC 's. Burlintong: Elsevier Newnes, 2004.

[2]. Siemens. Function Block Diagram (FBD) for S7-300 and S7-400 Programing. Germany: Siemens AG, 2006.

[3]. Khasawneh, Hussam. Introduction to PLC and Ladder Logic. Amman: Faculty of Engineering and Technology Universitas Of Jordan, 2009.

[4]. Bryan, L.A. Programmable Controllers: Theory and Implementation. Second Edition. Atlanta: An Industrial Text Company Publication, 1997.

[5]. Hackworth, John. R and Hackworth.F.D. Programmable Logic Controllers: Programming Methods and Applications. Virginia: Pearson/Prentice Hall, 2004.

[6]. Permana Ngadi., Ferdinan Hendra, dan Leonardus. Perancangan Konseptual Sistem Transfer Pada Processing Work Station. Skripsi, Universitas Tarumanagara Jakarta, 2001.

[7]. Bolton, W. Programming Logic Controller. Fourth Edition. Burlington: Elsevier Newnes, 2006.

[8]. Soeharsono dan Supriyadi. Petunjuk Praktikum Pneumatik dan Elektropneumatik. Jakarta: Laboratorium Sistem Kontrol dan Otomasi Teknik Mesin Universitas Trisakti, 1999.

[9]. Setiawan, Iwan. Programmable Logic Controller dan Teknik Perancangan Sistem Kontrol. Yogyakarta: Andi Yogyakarta, 2006.

[10]. H. Arshid. Makalah Sistem Kompresor (On-Line). (Diakses 11 November 2014). 
[11]. Thiang dan Edwin Sugiarta. Sistem Otomasi Mesin Tempat Parkir Mobil Bawah Tanah dengan Menggunakan Programmable Logic Controller. Jurnal Teknik Mesin. Vol. 10. No. 2 (Oktober 2008): 94-101.

[12]. Suyanto dan Dedy Yulistyawan. Otomatisasi Sistem Pengendali Berbasis PLC pada Mesin Vacuum Metalizer untuk Proses Coating. Gematek Jurnal Teknik Komputer. Vol. 9. No. 2 (September 2007): 99-118.

[13]. Carmen. Sistem Otomasi Pada Feeding dan Lifting Station Dengan Menggunakan Programmable Logic Controler. Skripsi. Universitas Trisakti Jakarta, 2013.

[14]. M. Gere and J. Goodno. Mechanics of Materials. Canada: Toronto, 2009. 